\title{
International Year of Light 2015 opens new dimensions in optics and photonics education
}

\section{Dan Curticapean}

Dan Curticapean, "International Year of Light 2015 opens new dimensions in optics and photonics education," Proc. SPIE 9793, Education and Training in Optics and Photonics: ETOP 2015, 979308 (8 October 2015); doi:

$10.1117 / 12.2223056$

Event: Education and Training in Optics and Photonics: ETOP 2015, 2015, Bordeaux, France 


\title{
International Year of Light 2015 Opens New Dimensions in Optics and Photonics Education
}

\author{
Dan Curticapean*a \\ ${ }^{a}$ Offenburg University, Badstr. 24, 77652 Offenburg, Germany
}

\begin{abstract}
The United Nations have declared 2015 as the International Year of Light (IYL2015) and light-based technologies [1]. As a main result, the public interest is focused on both the achievements and the new frontiers of optics and photonics. This opens up new perspectives in the teaching and training of optics and photonics.

In the first part of the paper, the author presents the numerous anniversaries occurring in the International Year of Light 2015 together with their importance to the development of science and technology.

In the second part, we report on an interactive video projection at the opening ceremony of the IYL2015 in Paris on January 19-20, 2015. Students of Offenburg University have established an interactive video projection which visualizes Twitter and Facebook messages posted with the hashtag \#iyl2015 in a mapping technique. Thus, the worldwide community can be interactively part of the opening ceremony.
\end{abstract}

Finally, upcoming global community projects related to optics and astronomy events are presented.

Keywords: Education in Optics and Photonics, International Year of Light and Light-Based Technologies

\section{INTRODUCTION}

"The photon is for this century what the electron was for the last." This well-known statement is frequently made by physicists and other scientists to express a major current research trend, but also to point out that fundamental inventions and innovative technologies are to be expected from the field of optics and photonics in coming years. Research findings on the optical frequency comb, in attosecond laser science and plasmonics, to name only a few, have given us an idea of the enormous potential of optics and photonics. We are going through exciting times, maybe even comparable to the last few years of the nineteenth century, when German physicist Karl Ferdinand Braun built the first cathode ray tube (CRT) in 1897 - still called the "Braun tube" in German-speaking countries and in Japan - which paved the way for the development of the oscilloscope and television technology [2].

Similarly in the 1950s, American physicist Charles Townes developed an idea of how to amplify microwaves but also light, initiating the triumphant course of the laser [3]. Today, everyday life seems impossible to imagine without laser technology. Albert Einstein, however, had described how light could be amplified as early as in a 1915 publication [4]- [5], the centenary of which was one of the reasons that 2015 was proclaimed as the International Year of Light (IYL2015). Incidentally, all these three researchers received the highest scientific honor for their findings, the Nobel Prize in Physics.

In light of several relevant anniversaries, and to recognize the achievements and the impact of optically-based technologies,

*dan.curticapean@hs-offenburg.de

Education and Training in Optics and Photonics: ETOP 2015, edited by Eric Cormier, Laurent Sarger Proc. of SPIE Vol. 9793, 979308 - (C) 2015 SPIE, IEEE, OSA, ICO · doi: 10.1117/12.2223056 
the EPS, SPIE, OSA and further science organizations recommended 2015 as the International Year of Light to the UN. After numerous preparations - also including a small contribution by Offenburg University, a poster series called The Magic of Light [6], the proposal succeeded: On 20 December 2013, the UN General Assembly 68th Session proclaimed 2015 as the International Year of Light and Light-Based Technologies (IYL 2015) [1].

The objective of the IYL2015 is to emphasize the importance of light and light-based technologies in the medical field, in communication, energy engineering, education, fundamental research as well as in daily life. The advancement of optical technologies is vital for the well-being of our society. At the same time, the impact of light in the arts, for culture and entertainment shall be emphasized as well. A socio-political dimension of the IYL2015 is the call for securing access to light for all, when many people around the world still do not have light at night or only have kerosene lamps.

\section{MILESTONES 2015 IN LIGHT SCIENCE}

Several major anniversaries in 2015 [6]-[7] shall add to the attractiveness of the 2015. Among them are:

1015: Alhazen, Arabian mathematician, physicist and optician -inventor of the magnifying lens (loupe) -, completes his seven-volume treatise, "Treasure of Optics"

1615: French-Huguenot engineer Salomon de Caus invents the prototype of a solar-driven engine

1815: Augustin-Jean Fresnel introduces the theory of light as a wave

1865: James Clerk Maxwell rigorously describes the electromagnetic theory of light

1905: Albert Einstein published the explanation of the photoelectric effect, which earned him the Nobel Prize

1915: David Hilbert and Albert Einstein develop the theory of relativity, showing how light is at the center of the very structure of space and time

1965: Arno Allan Penzias and Robert W. Wilson discover the cosmic microwave background, an electromagnetic echo of the very creation of the universe

1965: Charles Kuen Kao and optical fiber technology

Not least, young people, school and university-level students shall be motivated and inspired by the exciting innovations and vitas of these celebrated scientists.

\section{OPENING CEREMONY OF THE INTERNATIONAL YEAR OF LIGHT AT THE UNESCO}

The IYL2015 kicked off on January 19-20, 2015, with the opening ceremony at the UNESCO Headquarters in Paris, with more than 1100 invited guests from all over the globe, representatives from science, politics and culture. The opening ceremony started with a video message by UN SecretaryGeneral Ban Ki Moon (Fig. 1). Talks by as many as five Nobel laureates - Zhores Alferov, Steven Chu, Serge Haroche William Phillips, and Ahmed Zewail - markedly affected the high level of the academic part of the event.

A cultural highlight was the premiere performance of Bruce Adolphe's composition "Einstein's Light" by star violinist Joshua Bell and pianist Marija Stroke.

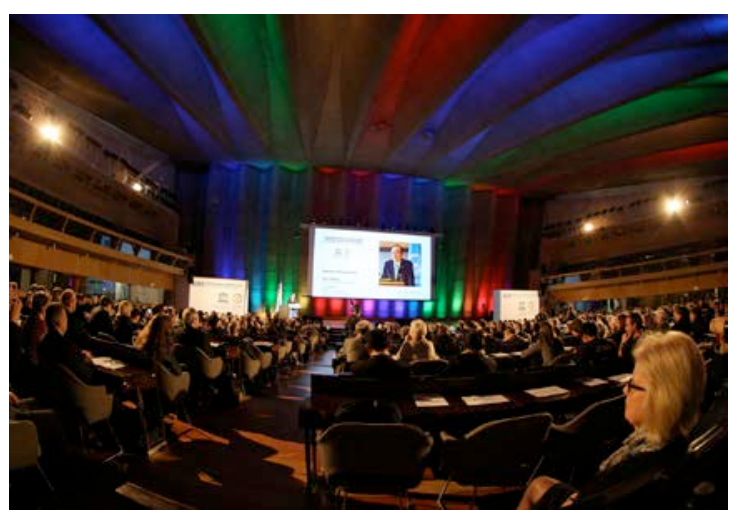

Fig. 1: UN Secretary-General Ban Ki Moon, video message for the IYL 2015 

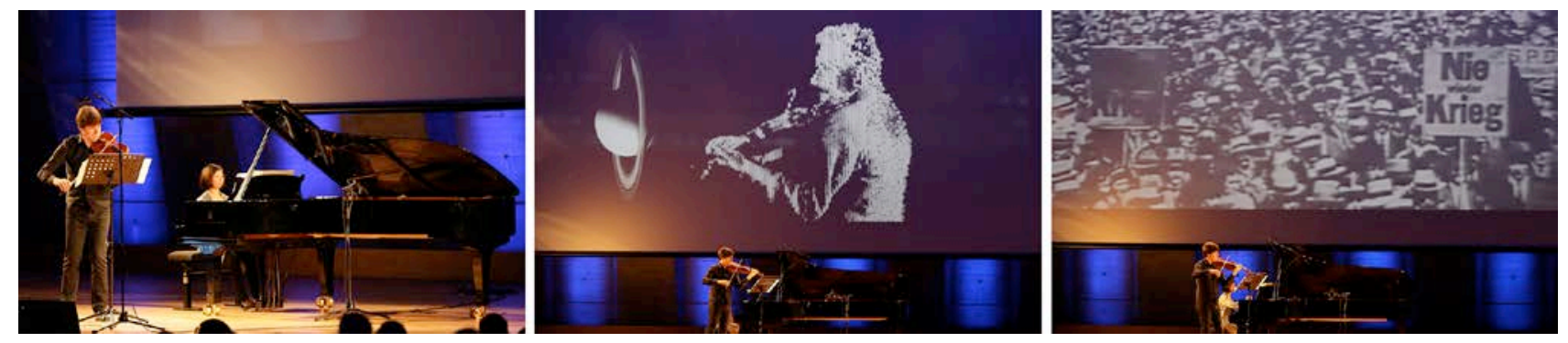

Fig. 2: Violonist Joshua Bell interpreting "Einstein’s Light” by Bruce Adolphe

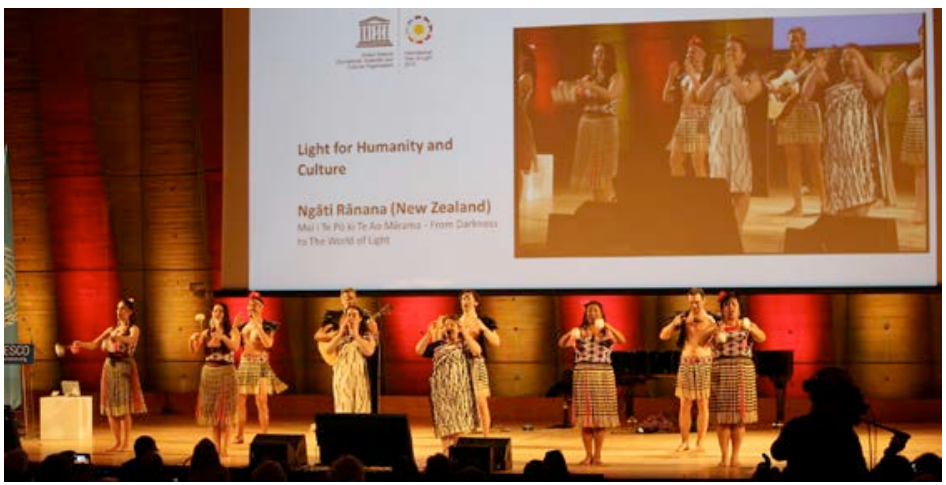

The folklore group Ngati Ranana from New Zealand with their performance "Mai i Te Po ki Te Ao Marama - From Darkness to the World of Light" underscored the contribution of light for humanity and culture.

Fig. 3 (left): Folklore group Ngati Ranana on the UNESCO stage

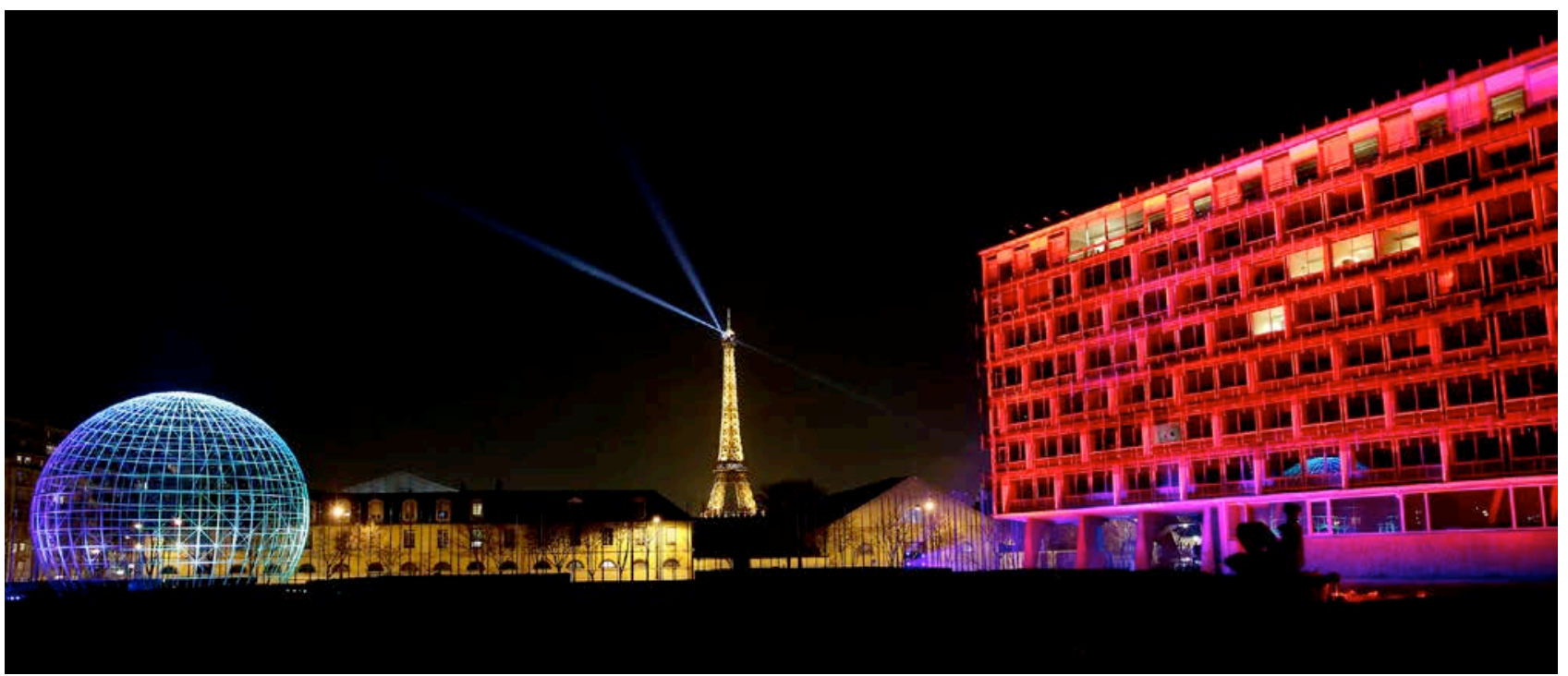

Fig. 4: "Light is Here," an impressive light projection onto the UNESCO building by Finnish video artists

During the opening ceremony, Offenburg University students presented an interactive projection in the UNESCO Foyer. Several other projects ensued at the University from the exciting prospect of the IYL2015, including:

- IYL2015 art poster collection

- "Smart Interactive Projection"

- "Invisible Light"

- University for Children

- "Students Meet Scientists"

- Live broadcasting of the total lunar eclipse

They are briefly described in the following. 


\section{INTERNATIONAL YEAR OF LIGHT ART POSTER COLLECTION}

As described in earlier papers [6], we managed to prepare a whole poster series in the framework of the IYL2015. It should be emphasized that this was an interdisciplinary project open to anyone, i.e. not just students of physics. Figure 5 shows a selection of the best works, combined on a postcard which was used for promotional purposes in the run-up to the IYL2015.

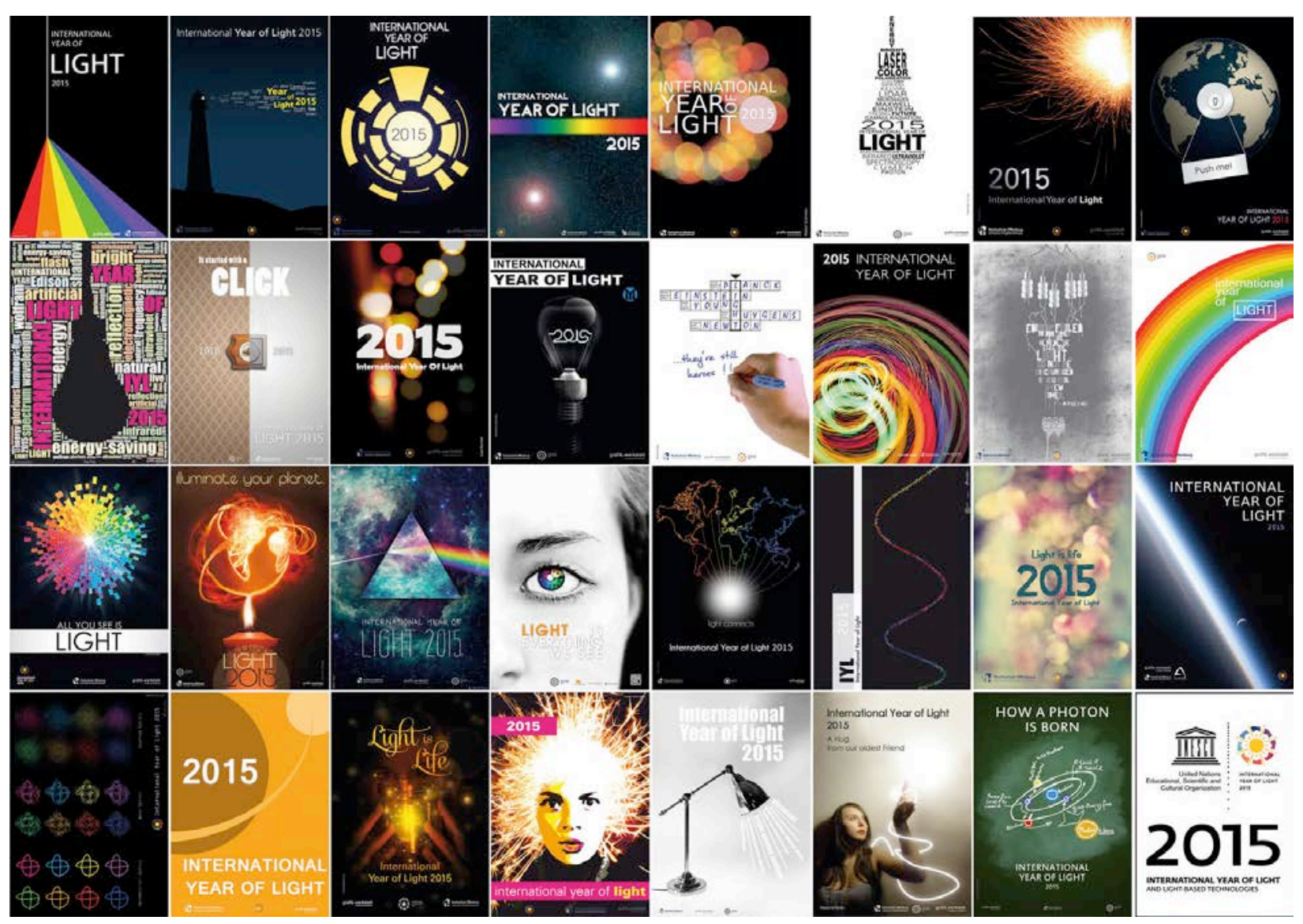

Fig. 5: Artwork poster: Magic of Light; (C) www.Offenburg-University.de/iyl2015

This selection, in a larger poster format, was exhibited at:

- International Congress Center at Laser Munich (May 2013): European Conference on Lasers; Electro-Optics, International Quantum Electronics Conference OSA, EPS, Optical Metrology 2013SPIE

- Education \& Training in Optics \& Photonics in Porto (July 2013): OSA, SPIE, EPS Conference

- Optics \& Photonics in San Diego (August 2013): SPIE Conference

- Frontiers in Optics in Orlando (October 2013): OSA Conference

- Allied Arts of Whatcom County in Bellingham, WA/USA (January 2014) [8]-[9]

- Opening Ceremony, UNESCO Headquarters in Paris (19-20 January 2015) 


\section{INVISIBLE LIGHT}

A group of students also worked on an interactive smartphone app (Fig. 6), as well as on the question what light actually means for us as humans. On the corresponding website (Fig. 7), http://www.invisible-light-project.com, users gain insights into various aspects of optics, photonics and other light-related issues, but can also post and share contents on their own. The smartphone app visualizes the information and transmits it to end users in real time. The project is presented in more detail in a paper titled "Invisible Light" - A global infotainment community based on augmented reality technologies [10]. The project is also showcased by Wikitude [11] at:

http://www.wikitude.com/showcase/invisible-light-project-wikitude-hs-offenburg-international-year-light-2015/.

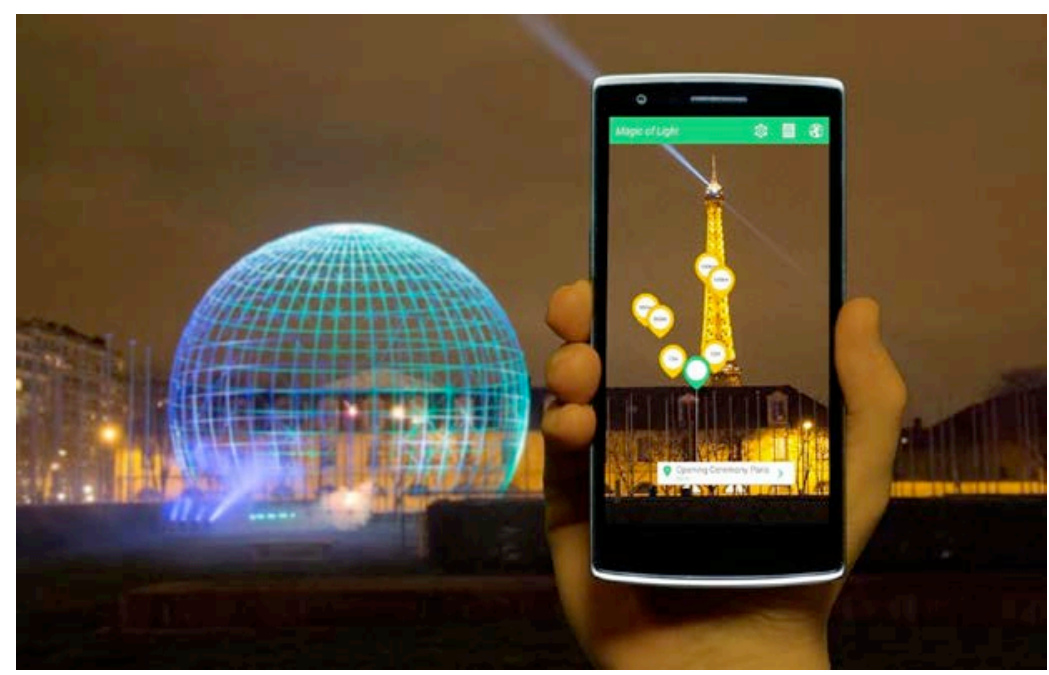

Fig. 6: Invisible Light App

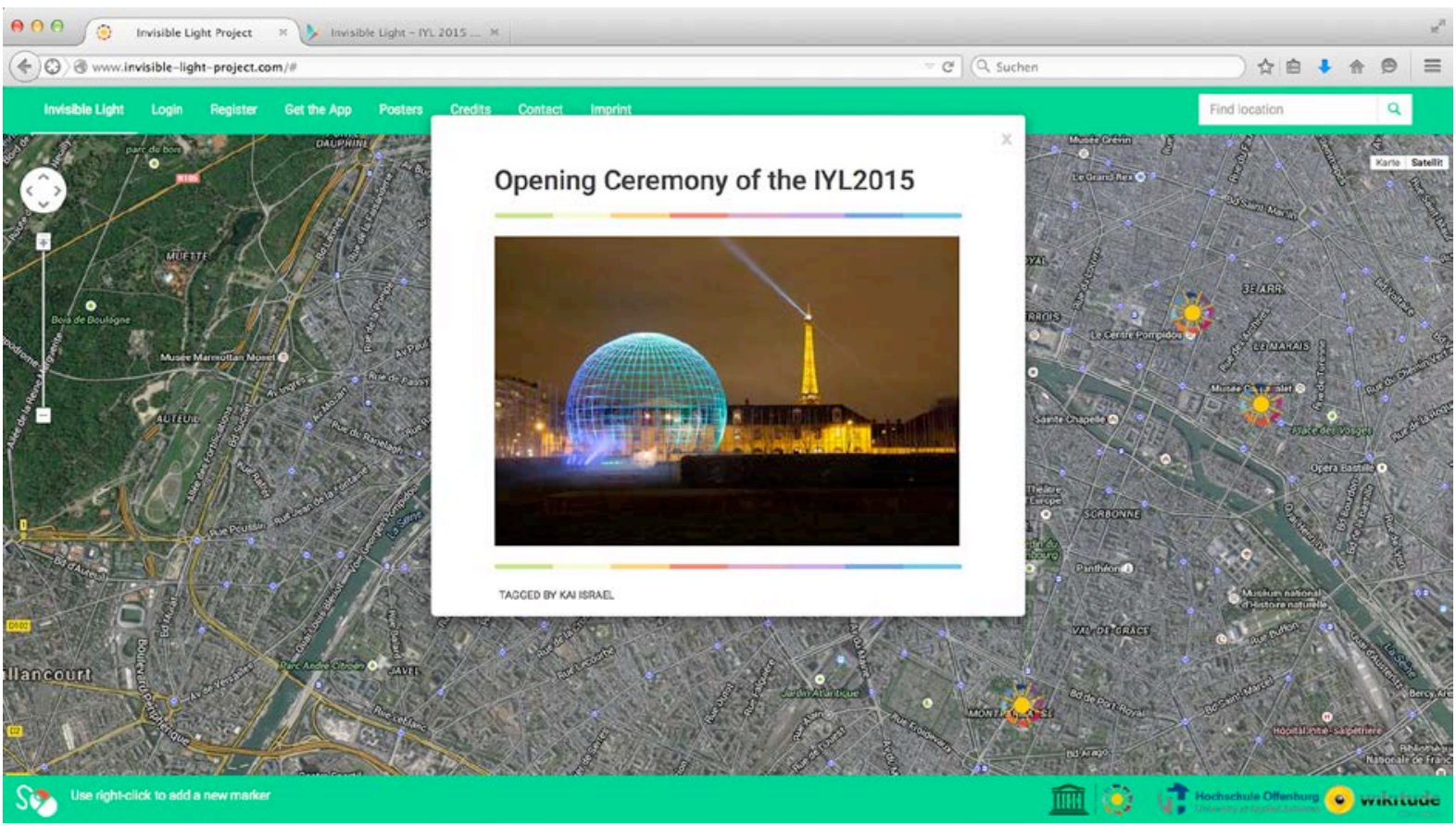

Fig. 7: Invisible Light website with markers for the IYL2015 opening ceremony 


\section{SMART INTERACTIVE PROJECTION}

The "Smart Interactive Projection" (Fig. 8) was shown in the foyer of the Paris UNESCO building during the two days of the opening ceremony of the IYL2015, next to works by Picasso, Miró or Salvador Dalí. Tweets placed for the opening ceremony by participants around the world - not just those present in Paris - were visualized in an interactive projection. Using the hashtag \#iyl2015, Twitter messages could be sent to Paris and were then placed on a world map showing the users' locations and messages. The interactive map highlighted the regions from which tweets originated in different colors. According to the number of tweets, the colors of the regions also changed, from yellow to dark red. In addition, the projections were streamed onto the IYL2015 website, so the Twitterers were able to receive feedback and thus actively participate in the opening even if they not be there.

In the two days of the opening ceremony, approximately 15,000 tweets from around the globe were registered and placed on the map. With the installation, our students were able to apply their new knowledge and skills in an exciting project, dedicated to the

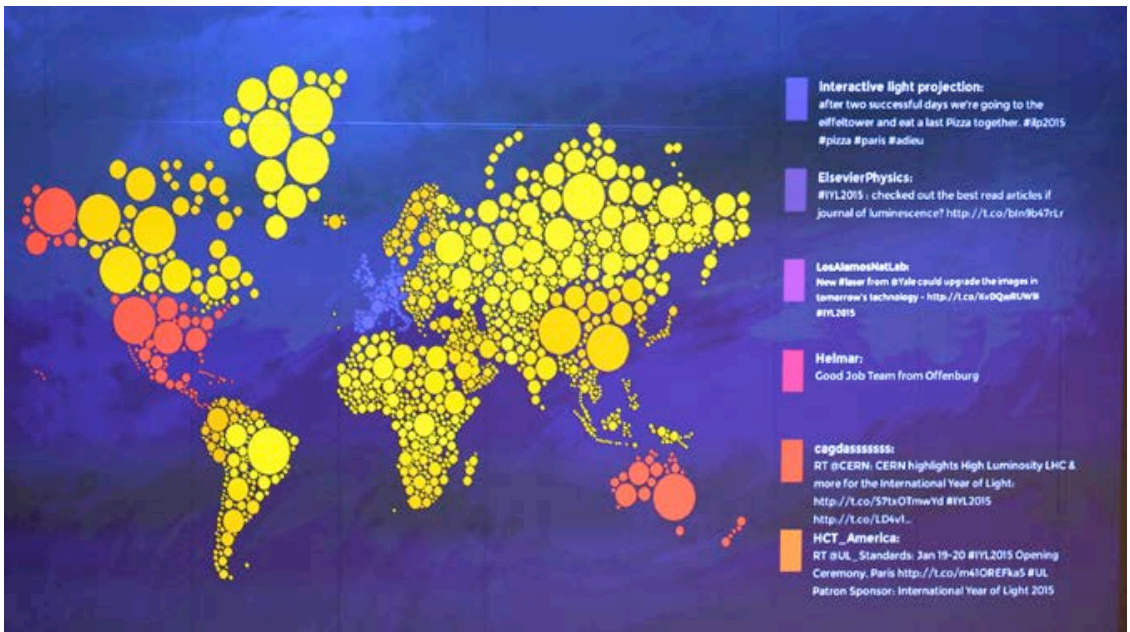

Fig. 8: Smart Interactive Projection - World map visualizing the tweets IYL2015.

In addition to the installation, we set up a small studio in the foyer where we asked a number of well-known personalities from the world of optics and photonics for a short statement, including Nobel prizewinner William Phillips, SPIE CEO Dr. Eugene Arthurs, and SPIE President Philip Stahl.

\section{UNIVERSITY FOR KIDS - THE MAGIC OF LIGHT I + II}

One of Offenburg University's most popular lecture series, the semiannual "KinderUni" (University for Children) provides direct insights into the exciting world of science to junior researchers aged 8-12. This year, the lectures focused on the topics of light, optics and photonics. In the winter semester, "The Magic of Light" covered basic concepts of optics and photonics such as reflection, refraction, total internal reflection, light is energy, speed of light, laser, optical fibers, and their various applications [12]-[13].

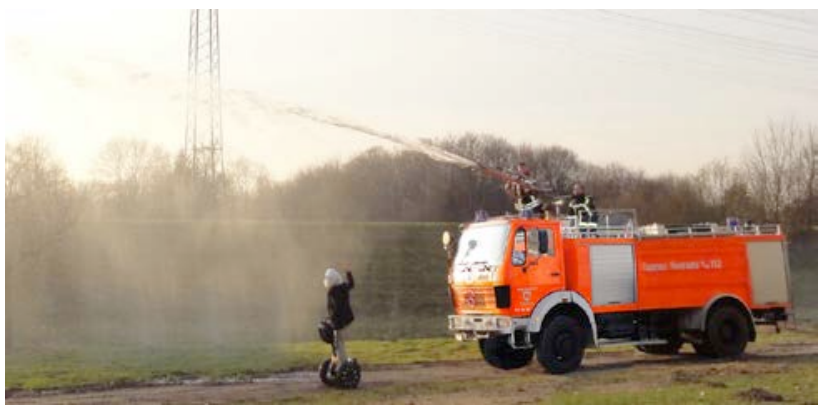

The lecture had a highly experimental and illustrative approach so kids could easily follow and understand optical phenomena. For instance, the question of why we can still see stars that have long ceased to exist was explained with an analogy to water jets, which we demonstrated by inviting over a fire truck team (Fig. 9).

Fig. 9: Fire-truck team's demonstration at the KinderUni 
At the next KinderUni of the summer semester, the Magic of Light lecture will continue with "Across the Universe with Relativity and Quantum Theory." Some thought experiments will be presented, along with interesting experiments involving liquid nitrogen. The "twin paradox," black holes and the 1919 solar eclipse - which confirmed Einstein's relativity theory - will also be covered. The lecture will conclude with the fascinating effect of a Levitron experiment. More details of this lecture will be presented in an upcoming paper.

\section{TOTAL LUNAR ECLIPSE}

Astronomical phenomena have fascinated people since the very beginning of mankind. They have an inspiring effect, especially on young people. We have demonstrated our expertise in live broadcasting of lunar eclipses on our website, www.eclipse-live.com. The impact factor of our last live broadcast was huge, with more than 36,000 viewers from more than 150 different countries. We have reported about our experiences in a previous paper, "Astronomical phenomena: Events with high impact factor in teaching Optics and Photonics" [13]-[14]. Also the iBook "Moonbook" realized by our students can be downloaded for free [15].

In the early hours of September 28 this year, we will experience a total lunar eclipse in large parts of Europe and North America. This also being the IYL2015, we want to turn the lunar eclipse into a global event and recruit as many 'participants' as possible through our website [16]. We will report live from major astronomical observatories around the world, conduct live interviews with many scientists and cover a great range of astronomical topics. High-school and university students will be especially encouraged to actively participate.

We invite everyone to take part in the live broadcast of the total lunar eclipse on September 28. For more information, go to:

www.eclipse-live.com.

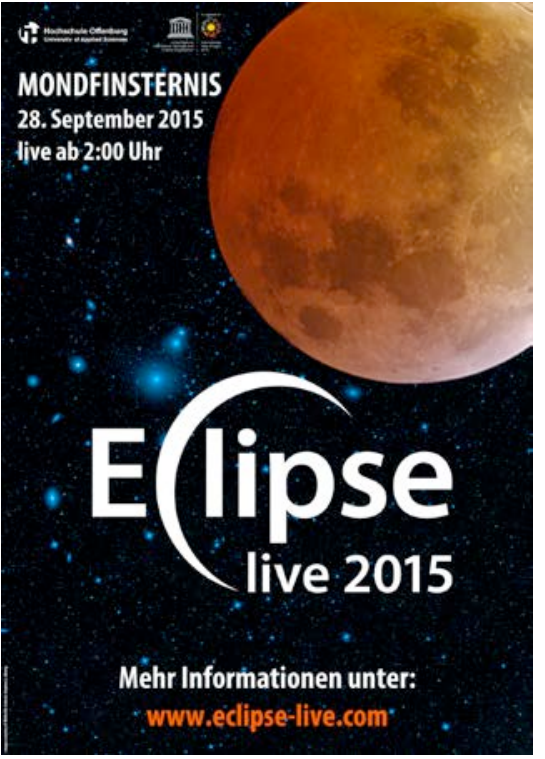

Fig. 10: Total Lunar Eclipse

\section{STUDENTS MEET SCIENTISTS}

The objective of this lecture series is to inform and inspire our students about the fascinating world of research. In the IYL2015 we were able to bring in Google Glass developer Dr. Bernhard Kress for a presentation. Dr. Kress is a SPIE Fellow and was an invited speaker at the opening ceremony of the IYL2015 in Paris. Over the past twenty years, he has made significant scientific contributions as a researcher and author in the fields of micro-optics and diffractive optics. Dr. Kress holds 29 international patents and has published three books in the field of diffractive optics. He is currently with Google [X] working on the Google Glass project as the Principal Optical Architect [17]-[18].

In a captivating lecture on the development of modern displays, followed by lively discussion, our students learned a lot, and some of them may well have left resolved to go into research after graduation.

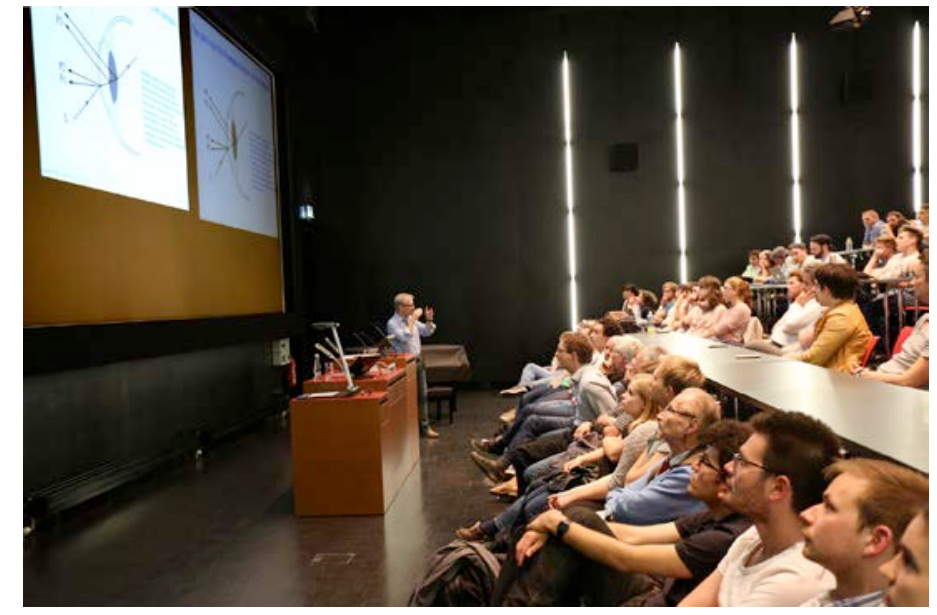

Fig. 11: Dr. Kress in Offenburg 


\section{CONCLUSIONS AND PERSPECTIVES}

We can conclude that the IYL has provided a motivation for our students to become involved in an interdisciplinary project revolving around optics and photonics. The presented projects included not only students of art, but also those studying media sciences, informatics or engineering. "Good projects appear when people are working in different areas." [7]

The impact factor of our projects was very high, both on regional and international levels. Furthermore, we were able to captivate the attention of people of all ages, from elementary scholars to seniors.

With the outstanding projects - University for Kids and live broadcast of the total lunar eclipse on September 28 - we hope to set further important accents.

Projects such as Invisible Light or smart projections are sustainable and can be further developed throughout the IYL2015.

With the live broadcast of the total lunar eclipse on the internet, we hope to establish a global action network on the IYL2015.

\section{ACKNOWLEDGMENT}

The author would like to thank all who supported him in the activities described in this article, especially Professor John Dudley, President of the European Physical Society ("Mister IYL2015"), and Dr. Eugene Arthurs, SPIE CEO; many thanks also to all the students at Offenburg University who helped implement these projects.

\section{REFERENCES:}

[1] United Nations, General Assembly, 68/221. International Year of Light and Light-Based Technologies 2015, Resolution adopted by the General Assembly on 20 December 2013 (2013)

[2] Vogel H., [Gerthsen Physik], Springer, Berlin, Heidelberg, New York, (1997)

[3] Townes Charles H., [How the Laser Happened: Adventures of a Scientist], Oxford University Press, New York, (1999)

[4] Einstein, A., „Quantentheorie der Strahlung”, Mitteilungen der Physikalischen Gesellschaft Zürich Nr. 18, (1916)

[5] Einstein, A., „Quantentheorie der Strahlung”, Phys. Z. 18 pp.121-128 (1917)

[6] Curticapean, D., „Photonics meet digital art”, Optics Education and Outreach III, Proceedings of SPIE, Vol. 9188-21, doi: $10.1117 / 12.2061861$, San Diego/USA (2014)

[7] Patricia Daukantas, "2015: The IYL”, Optics \& Photonics News 01/2015; p. 28-35; OSA Washington/USA (2015)

[8] SPIE, „SPIE TO CELEBRATE LIGHT IN ART AND TECHNOLOGY AT GALLERY SHOW” http://www.prweb.com/releases/2013/12/prweb11449343.htm (2013)

[9] http://calendar.bellinghamherald.com/bellingham wa/events/show/368966961-the-art-of-light-andtechnology (2013)

[10] Israel, K., Wozniak, P., Vauderwange, O., Curticapean, D., „Invisible Light” - A global infotainment community based on augmented reality technologies", 13th Education and Training in Optics and Photonics Conference, Bordeaux/France (forthcoming 2015)

[11] Wikitude GmbH, „Invisible Light Project - Wikitude in the International Year of Light 2015“, http://www.wikitude.com/showcase/invisible-light-project-wikitude-hs-offenburg-international-year-light2015/. (4 May 2015)

[12] Curticapean, D., „University for Children - The Magic of Light”, Proceedings: Eleventh International Topical Meeting on Education and Training in Optics and Photonics, St. Asaph, North Wales, United Kingdom (5-7 June 2009) 
[13] Curticapean, D., „Magic of Light”, Proc. SPIE 7783, Optics Education and Outreach, 77830I (31 August 2010); doi: $10.1117 / 12.862847,(2010)$

[14] Curticapean, D., „Astronomical phenomena: events with high impact factor in teaching optics and photonics", Proc. SPIE 9289, 12th Education and Training in Optics and Photonics Conference, 928909; doi: 10.1117/12.2070281 (2014)

[15] Cerkovniak, A., Hermanns, D., Nitsche, N., Stöferle, S., Wilke, R., [Moonbook], iBook, https://itunes.apple.com/de/artist/anika-cerkowniak/id599570824?mt=11 (2011)

[16] SPIE „SPIE OPTICS + PHOTONICS 2014 NEWS“ http://spie.org/x109249.xml (2014)

[17] Kress, B., „Optical toolkit enables wearable displays“, SPIE Newsroom, DOI: 10.1117/2.3201410.03 http://spie.org/x110601.xml (2014)

[18] Nelson, A., „Wearable technologies create new opportunities, raise questions“, SPIE Press Releases, 17 October 2014, http://spie.org/x110618.xml (2014) 